\title{
Pyrimidine nucleoside phosphorylase activity in tumour and matched normal gastrointestinal mucosa
}

\author{
B HIGLEY, JANE OAKES, J DE MELLO, and G R GILES \\ From the University Department of Surgery, St. James's University Hospital, Leeds
}

SUMMARY 5-Fluorouracil (5-FU) requires activation to the metabolites FdUMP and FUTP for its cytotoxic effect. This activation involves the intracellular enzymes uridine and thymidine phosphorylase. We have assayed the levels of these enzymes in colorectal and gastric cancers and have shown that, in the majority of cases, the enzyme levels were higher than in the adjacent normal mucosa. It is suggested that, while the ratio tumour/normal mucosa enzyme activity may give some indication of the relative toxicity of 5-FU in these tissues, the absolute activities of the phosphorylases in tumour tissue could give a better indication of tumour responsiveness.

5-Fluorouracil (5-FU) remains the most effective of the currently available cytotoxic drugs for use against gastrointestinal tumours. ${ }^{1-3}$ Only $20 \%$ of patients with advanced cancer, however, show a definitive response which, although short-lived, does double the mean survival time of responders over non-responders or untreated patients. As such a small percentage of patients respond to 5-FU therapy it is clearly desirable to identify those patients who are likely to respond and to avoid unnecessary treatment in the remainder.

It is generally accepted that 5-FU itself has no direct cytotoxic activity but exerts its influence via its active metabolites 5-fluorodeoxyuridine-5' monophosphate (FdUMP) which inhibits thymidylate synthetase activity thereby starving cells of TMP for DNA synthesis ${ }^{4}$ and 5-fluorouridine-5'triphosphate (FUTP) which becomes incorporated into RNA and seems to affect both RNA maturation and DNA synthesis. Recent evidence would seem to suggest that possibly it is the second metabolite FUTP which may exert the major cytotoxic influence. ${ }^{56}$ As nucleotides do not readily cross cell membranes it is logical to assume that activation will occur intracellularly and that the effect of the metabolites will be restricted to the activating cell.

Much work has been published attempting to relate cellular sensitivity to 5-FU with the activity of enzymes thought to be involved in this activation process. ${ }^{7-10}$ The enzymes uridine phosphorylase, uridine kinase, uracil phosphoribosyl transferase, and the nucleotide kinases are common for the activation of 5-FU to both FdUMP and FUTP

Received for publication 1 March 1982
(Figure). Thymidine phosphorylase and kinase and ribonucleotide reductase are more exclusively involved with activation to FdUMP. In this study we have assayed the levels of two of these activating enzymes uridine and thymidine phosphorylase within gastrointestinal mucosa and within matched samples of gastrointestinal carcinomas to determine whether the enzymes display a markedly different activity in the two tissues.

\section{Methods}

MATERIALS

Nucleosides were obtained from Sigma Chemical Co. Ltd. and 5-FU sodium salt from Hoffman La Roche. HPLC grade solvents from BDH or Fisons were used where indicated. All other reagents were of analytical grade obtained from $\mathrm{BDH}$.

PATIENTS AND PATIENT SAMPLING

Twenty eight patients were included in the

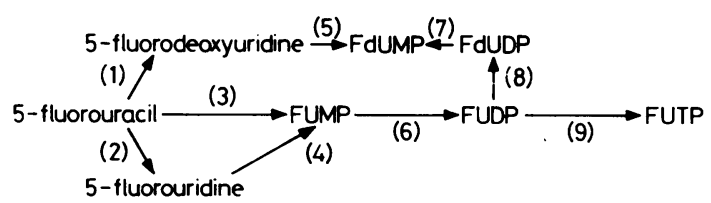

Fig. Possible routes of 5-FU activation. Key to enzymes:

(1) thymidine phosphorylase; (2) uridine phosphorylase;

(3) uracil phosphoribosyltransferase; (4) uridine kinase; (5) thymidine kinase; (6), (7) nucleoside monophosphate

kinase; (8) ribonucleotide reductase; (9) nucleoside diphosphate kinase. 
experiments, 15 males and 13 females. All were patients with gastrointestinal tumours and were subjected to surgical excision of the primary tumour. Fifteen of the patients received 5-FU from one to four days before operation and at this time most (13 patients) had the plasma pharmacokinetics of the drug monitored. The remaining 13 patients received no 5-FU. Tumour site was divided as follows: gastric, three; right colon, five; colon, seven; rectum, 13.

After the specimen was removed a piece of tumour ( $0.5 \mathrm{~g}$ minimum) and of normal mucosa (if possible no closer than $10 \mathrm{~cm}$ to the tumour) were randomly cut from it as soon as possible, frozen in liquid nitrogen, and stored at $-70^{\circ} \mathrm{C}$ for subsequent analysis.

The mean age of the patient group of 15 males and 13 females was $64 \cdot 5$ years (range $42-82$ years). After pathological examination of the resected specimen, all three gastric cancers proved to have lymph node metastases and the patients with colorectal cancer were staged as Dukes's B (12 patients); Dukes's C (10 patients). The three remaining patients had liver metastases.

\section{ENZYMATIC ANALYSIS}

A crude homogenate of tissue was prepared by weighing approximately $0.1 \mathrm{~g}$ tissue and homogenising it in 4 volumes of homogenising medium $(50 \mathrm{mM}$ potassium phosphate $+1 \mathrm{mM}$ EDTA + $5 \mathrm{mM} \beta$-mercaptoethanol pH 7.0). The homogenate was centrifuged at $100,000 \times g$ for 60 minutes at $4^{\circ} \mathrm{C}$ and the supernatant was then dialysed overnight against $\overline{500}$ volumes of homogenising buffer. The dialysed supernatant was used in the enzymatic reaction. The incubation medium contained at final concentration $75 \mathrm{mM}$ phosphate buffer ( $\mathrm{pH} 7 \cdot 5), 5 \mathrm{mM}$ substrate (thymidine, deoxyuridine or uridine), and tissue extract in a final volume of $300 \mu \mathrm{l}$. The reaction, performed at $37^{\circ} \mathrm{C}$, was started by the addition of 50 $\mu l$ tissue extract and stopped at $0,10,20$, and 30 minutes by the removal of $50 \mu \mathrm{l}$; this was then added to $50 \mu$ lice cold $0.8 \mathrm{M}$ perchloric acid. After protein precipitation and removal, $50 \mu \mathrm{l}$ of the resultant supernatant was added to $50 \mu \mathrm{l}$ of $0.8 \mathrm{mM}$ sodium bisulphite. This was stored at $-70^{\circ} \mathrm{C}$ for subsequent HPLC analysis for uracil or thymine as appropriate. The protein content of the tissue extract was determined by the biuret method. Activity is expressed as nmol base produced/mg protein $/ \mathrm{h}$.

\section{HPLC DETERMINATION OF URACIL OR THYMINE PRODUCTION}

Analyses were performed using a system consisting of a ACS 750/03 pump with a fixed wavelength UV detector 750/11 set at $254 \mathrm{~nm}$ connected to a Houston omniscribe chart recorder. Loading was manual using a Rheodyne 7125 injector with $10 \mu \mathrm{l}$ loop (Applied Chromotography Supplies, Luton, Beds.). Data reduction was by manual peak height measurement. More recently the analysis has used a LDC constrametric III pump, spectromonitor III variable UV detector set at $254 \mathrm{~nm}$, loading was with a Magnus Autosampler (Magnus Scientific) fitted with a $20 \mu$ l loop and data reduction was by automated peak height measurement using a CCM (Lab. Data Control (UK), Stone, Staffs.). Samples were eluted from a $250 \times 4 \mathrm{~mm}$ Spherisorb S5 0DS column using either phosphoric acid $\mathrm{pH} 3.0$ at 1.0 $\mathrm{ml} / \mathrm{min}$ in the case of deoxyuridine and uridine phosphorylase, or $50 \mathrm{mM}$ phosphate buffer $\mathrm{pH} 3.0$ containing $10 \%$ methanol in the case of thymidine phosphorylase. Although elution volumes on the two systems (ACS vs LDC) varied a little, results were reproducible within $1 \%$ provided that the standards, run through each appropriate system, were used for quantification. External standardisation using uracil or thymine standards run daily were used throughout.

\section{STATISTICAL ANALYSIS}

Data were analysed by a modified rank-sum test (unpaired) or Wilcoxon signed rank test (paired) where appropriate. the degree of correlation was ascertained by Spearman's rank correlation coefficient. Significance was accepted at $p<0 \cdot 06$.

\section{Results}

\section{EFFECT OF AGE ON PHOSPHORYLASE LEVELS}

There was no significant correlation between the age of the patient and the tissue levels of deoxyuridine phosphorylase or uridine phosphorylase in normal or tumour tissue nor when the tumour/normal mucosal ratio was calculated. There was, however, a degree of positive correlation between increasing age and thymidine phosphorylase in normal mucosa $(\mathrm{Rs}=0 \cdot 478, \mathrm{p}<0 \cdot 02)$ but not tumour tissue.

\section{EFFECT OF SEX OF PATIENT}

There was no statistical difference between the results obtained for males and females with regard to any of the phosphorylase activities measured in either tumour or normal mucosa, although females did display a slightly higher average activity than males in both tissues and with all three phosphorylases. The range of phosphorylase levels in normal and cancerous tissue is shown in Table 1.

EFFECT OF MUCOSAL SITE

In normal mucosa deoxyuridine phosphorylase was 
Table 1 Pyrimidine nucleoside phosphorylase activity

\begin{tabular}{|c|c|c|c|c|c|c|}
\hline & \multicolumn{2}{|c|}{ Uridine phosphorylase } & \multicolumn{2}{|c|}{ Thymidine phosphorylase } & \multicolumn{2}{|c|}{ Deoxyuridine phosphorylase } \\
\hline & Tumour & $\begin{array}{l}\text { Normal } \\
\text { mucosa }\end{array}$ & Tumour & $\begin{array}{l}\text { Normal } \\
\text { mucosa }\end{array}$ & Tumour & $\begin{array}{l}\text { Normal } \\
\text { mucosa }\end{array}$ \\
\hline $\begin{array}{l}\text { All patients (28) } \\
\text { Post-5-FU (15) } \\
\text { No 5-FU (13) }\end{array}$ & $\begin{array}{l}90 \cdot 0 \pm 48 \cdot 8^{*} \\
89 \cdot 0 \pm 50 \cdot 1 \\
91 \cdot 1 \pm 49 \cdot 3\end{array}$ & $\begin{array}{l}63 \cdot 7 \pm 41 \cdot 8 \\
61 \cdot 7 \pm 35 \cdot 1 \\
65 \cdot 9 \pm 49 \cdot 8\end{array}$ & $\begin{array}{l}397 \cdot 6 \pm 208 \cdot 2 \\
404 \cdot 3 \pm 209 \cdot 2 \\
389 \cdot 8 \pm 215 \cdot 3\end{array}$ & $\begin{array}{l}292 \cdot 1 \pm 139 \cdot 3 \\
276 \cdot 2 \pm 131 \cdot 8 \\
310 \cdot 5 \pm 150 \cdot 7\end{array}$ & $\begin{array}{l}792 \cdot 2 \pm 285 \cdot 7 \\
695 \cdot 0 \pm 367 \cdot 9 \\
904 \cdot 3 \pm 389 \cdot 1\end{array}$ & $\begin{array}{l}439 \cdot 1 \pm 218 \cdot 9 \\
347 \cdot 6 \pm 152 \cdot 8 \\
544 \cdot 7 \pm 240 \cdot 9\end{array}$ \\
\hline $\begin{array}{l}\text { Tumour site } \\
\text { Stomach (3) } \\
\text { Caecum (5) } \\
\text { Colon (7) } \\
\text { Rectum (13) }\end{array}$ & $\begin{array}{r}77 \cdot 3 \pm 64 \cdot 3 \\
76 \cdot 7 \pm 29 \cdot 5 \\
122 \cdot 2 \pm 62 \cdot 3 \\
80 \cdot 6 \pm 40 \cdot 3\end{array}$ & $\begin{array}{l}19 \cdot 0 \pm 12 \cdot 5 \\
83 \cdot 4 \pm 70 \cdot 7 \\
71 \cdot 6 \pm 15 \cdot 6 \\
62 \cdot 1 \pm 37 \cdot 6\end{array}$ & $\begin{array}{l}222 \cdot 3 \pm 65 \cdot 0 \\
374 \cdot 9 \pm 178 \cdot 3 \\
474 \cdot 3 \pm 292 \cdot 6 \\
405 \cdot 4 \pm 179 \cdot 0\end{array}$ & $\begin{array}{l}190 \cdot 6 \pm 108 \cdot 5 \\
384 \cdot 2 \pm 163 \cdot 5 \\
277 \cdot 9 \pm 105 \cdot 9 \\
287 \cdot 8 \pm 144 \cdot 7\end{array}$ & $\begin{array}{l}644 \cdot 2 \pm 442 \cdot 2 \\
780 \cdot 8 \pm 260 \cdot 9 \\
932 \cdot 3 \pm 624 \cdot 7 \\
755 \cdot 2 \pm 256 \cdot 7\end{array}$ & $\begin{array}{l}279 \cdot 5 \pm 170 \cdot 6 \\
637 \cdot 4 \pm 150 \cdot 8 \\
427 \cdot 0 \pm 225 \cdot 0 \\
406 \cdot 2 \pm 214 \cdot 6\end{array}$ \\
\hline
\end{tabular}

${ }^{*}$ Mean \pm standard deviation.

significantly higher $(p<0.05)$ in the caecum than in either stomach or rectum $(637.4 \pm 150.8$; $279.5 \pm 170.6$ and $406.2 \pm 214.6$ respectively) and also higher than the rest of the colon $(\mathrm{p}<0.053)$. Uridine phosphorylase was significantly lower $(p<0.001)$ in the stomach than colon $(71.6 \pm 15.6$ and $19.0 \pm 12.5$ respectively) and thymidine phosphorylase activity was only significantly higher in caecum than either stomach or rectum $(p<0.036$ and $p<0.028$ respectively) and lower in rectum than colon $(p<0.026)$. It was found that the only statistically significant difference between tumours from different sites of the gut was that thymidine phosphorylase activity was lower in gastric than in colorectal cancer $(<0 \cdot 058)$.

\section{EFFECT OF TUMOUR STAGE}

With respect to Dukes's classification, deoxyuridine phosphorylase activity was greater in tumour tissue of Dukes's B patients than Dukes's D patients $(831.6 \pm 266.3 ; 210 \cdot 8 \pm 180.4$ respectively, $p<0.05)$ and all three enzyme activities were lower in the tumours of Dukes's D patients than in Dukes's C patients (thymidine, $\mathrm{p}<0.056$; deoxyuridine, $\mathrm{p}<0.056$; uridine, $\mathrm{p}<0.032$ ). There were no differences between Dukes's classification patients for any of the phosphorylase activities in normal mucosa.

\section{EFFECT OF 5-FU THERAPY}

It was noted that the average activity of the enzymes was slightly lower in patients who had received 5-fluorouracil before surgery than those who had not, but that this difference was statistically significant $(p<0.05)$ only for deoxyuridine phosphorylase activity in normal mucosa.

\section{COMPARISON OF TUMOUR TISSUE WITH NORMAL} MUCOSA

In the majority of cases phosphorylase activity was higher (ratio $>1 \cdot 1$ ) in tumour than in normal mucosa (thymidine, 16/28; deoxyuridine, 21/23; uridine, 19/28). This was true both for males $(8 / 15$, $11 / 14$, and 9/15) and females $(8 / 13,10 / 13$, and 10/13). An attempt was made to discern whether there was any correlation between pyrimidine nucleoside phosphorylase activity in the tumour and normal mucosa and it was found that there was some correlation $(R s=0.561, p<0.02)$ with respect to thymidine phosphorylase but not deoxyuridine or uridine phosphorylase.

It would seem that results obtained for the three enzymes differ somewhat qualitatively as well as quantitatively and for this reason Spearman's rank correlation was used to compare the activities of the different phosphorylases in the different tissues and the ratios obtained. It was found that there was a good degree of correlation between the activities of all three enzymes in tumour tissue (thymidine vs deoxyuridine, Rs $=0.762$; deoxyuridine vs uridine, $R s=0.626$; uridine $v s$ thymidine, $R s=0.579$; for all $\mathrm{p}<0.02$ ) but that in normal mucosa there was only good correlation between thymidine and deoxyuridine $(R s=0.739, p<0.02)$ and very poor correlation between thymidine and uridine $(R s=0.337, p<0.1)$ and between uridine and deoxyuridine $(R s=0.373, p<0 \cdot 1)$.

This pattern of correlation in the normal mucosa was mirrored by the tumour/normal mucosa ratio (Table 2) in which there was good correlation between thymidine and deoxyuridine ( $R s=0.787$, $\mathrm{p}<0.02)$ but poorer correlation between thymidine and uridine ( $R s=0.354, \mathrm{p}<0.1)$ and between uridine and deoxyuridine $(R s=0.379, p<0 \cdot 1)$. The above would seem to indicate that possibly the ratio is more dependent on changes in the normal mucosa activity of these enzymes than on their activity in tumour tissue and, in fact, when rank correlations were performed of tumour $v s$ ratio and normal mucosa $v s$ ratio it was found that the correlation was 
Table 2 Ratio of pyrimidine nucleoside phosphorylase activities in tumour vs paired normal mucosa

\begin{tabular}{|c|c|c|c|c|c|c|}
\hline \multirow{3}{*}{$\begin{array}{l}\text { Tumourl } \\
\text { normal } \\
\text { mucosa }\end{array}$} & \multicolumn{6}{|c|}{ No. patients } \\
\hline & \multicolumn{2}{|c|}{$\begin{array}{l}\text { Thymidine } \\
\text { phosphorylase }\end{array}$} & \multicolumn{2}{|c|}{$\begin{array}{l}\text { Deoxyuridine } \\
\text { phosphorylase }\end{array}$} & \multicolumn{2}{|c|}{$\begin{array}{l}\text { Uridine } \\
\text { phosphorylase }\end{array}$} \\
\hline & $\begin{array}{l}\text { No } \\
5-F U\end{array}$ & $5-F U$ & $\begin{array}{l}\text { No } \\
5-F U\end{array}$ & $5-F U$ & $\begin{array}{l}\text { No } \\
5-F U\end{array}$ & $5-F U$ \\
\hline 0.5 & 0 & 0 & 0 & 0 & 2 & 0 \\
\hline $0.51-0.9$ & 2 & 5 & 1 & 3 & 1 & 4 \\
\hline $0.91-1.09$ & 3 & 1 & 3 & 0 & 1 & 1 \\
\hline $1 \cdot 10-1 \cdot 5$ & 3 & 3 & 1 & 2 & 2 & 1 \\
\hline $1 \cdot 51-2 \cdot 0$ & 1 & 0 & 1 & 3 & 1 & 4 \\
\hline $2 \cdot 01-2 \cdot 5$ & 2 & 3 & 3 & 1 & 3 & 2 \\
\hline $2 \cdot 51-3 \cdot 0$ & 0 & 0 & 2 & 2 & 0 & 1 \\
\hline$>3.0$ & 1 & 3 & 2 & 4 & 3 & 2 \\
\hline
\end{tabular}

always better with normal mucosa than with tumour (thymidine-tumour, Rs $=0.400$; normal mucosa, $R s=0.436$; deoxyuridine-tumour, $R s=0.478$; normal mucosa, $\mathrm{Rs}=0.677$; uridine-tumour, Rs=0.296; normal mucosa, Rs=0·709).

\section{Discussion}

At this stage there is not enough clinical follow-up information on the 28 patients in this study to allow for any conclusions to be reached about the possible usefulness of pyrimidine nucleoside phosphorylase activity as a predictor of tumour response to 5-FU. Nor has the study revealed a clearly defined subgroup of patients with greatly increased or decreased activity of any of the enzymes measured in either tissue or in the tumour/normal mucosa ratio which could be postulated to correspond with responder or non-responder status. It would seem likely, in view of the fact that equilibrium for these enzymes favour nucleoside formation, that a higher enzyme activity in the presence of sufficient pentose1-phosphate could correlate with enhanced tumour sensitivity. ${ }^{10}$

It is interesting to note that tumour site does not seem to affect the activity of the pyrimidine nucleoside phosphorylases. The fact that tumour levels of the enzymes are higher than in normal mucosa may be an indication that the tumours are growing faster or capable of more rapid replication than the surrounding mucosa. Thymidine phosphorylase tissue distribution studies ${ }^{11}$ would seem to indicate that an increased relative growth rate is associated with increased activity of the phosphorylase but it is not clear whether this is due to an increase in the 'salvage' function or to the catabolic activity acting as a damper on the increase in thymidine concentration (thymidine is known to inhibit cell growth at high concentrations).

A number of studies have demonstrated that tissue from a variety of sources contains more than one pyrimidine nucleoside phosphorylase ${ }^{12-14}$ and that the spectrum of activity with the different substrates (uridine, deoxyuridine, and thymidine) varies with the differing enzyme or isoenzyme. The present study would seem to indicate that there is possibly more than one enzyme involved in the present system. Yamada ${ }^{12}$ has suggested that thymidine phosphorylase from rat liver will display activity with both thymidine and deoxyuridine, while the uridine phosphorylases can use all three substrates. If this is so in the human intestine, then it would seem from the correlation data presented here that thymidine phosphorylase and uridine phosphorylase are making a different contribution to total pyrimidine nucleoside phosphorylase activity in tumour and normal mucosa. In the present study it appears that the predominant enzyme in tumour tissue is probably uridine phosphorylase because there was enhanced activity against all three substrates. In normal mucosa, however, the major contribution would seem to be from thymidine phosphorylase, as there was only good correlation between the activities with thymidine and deoxyuridine as substrate.

When the activity of pyrimidine nucleoside phosphorylase in tumour and in normal mucosa is correlated with the ratio of activities in the two tissues we found that the negative correlation with normal mucosa was always slightly better than the positive correlation with tumour activity. This was particularly so when the substrate was uridine or deoxyuridine. From this it might be concluded that in the case of pyrimidine nucleoside phosphorylase the tumour/normal mucosa ratio is more dependent on differences in the activity of the enzyme in normal mucosa than in tumour and hence that, while the ratio may be a useful indicator of the relative potential toxicity of 5-FU to tumour and normal mucosa, the absolute tumour activity might be a better indicator of tumour responsiveness.

\section{References}

1 Carter SK. Cancer treatment today and its impact on drug development with special emphasis on the Phase II Clinical Trial. J Natl Cancer Inst 1976; 57: 235-44.

2 Moertel CG. Clinical management of advanced gastrointestinal cancer. Cancer 1975; 36: 675-82.

3 Savlov ED, Sherman CD Jr, Hall TC, Nahhas WA. Response and survival in advanced carcinoma without 
severe antitumour drug toxicity. Dis Colon ${ }^{~}$ Rectum 1970; 13: 421-4.

4 Langenbach RJ, Danenberg PV, Heidelberger C. Thymidylate synthetase: mechanism of inhibition by 5-fluoro-2'-deoxyuridylate. Biochem Biophys Res Commun 1972; 48: 1565-71.

5 Spiegelman S, Nayak R, Sawyer RC, Stolfi RL, Martin D. Potentiation of the anti-tumour activity of 5-FU by thymidine and its correlation with the formation of (5-FU) RNA. Cancer 1980; 45: 1129-34.

6 Martin DS, Stolfi RL, Sawyer RC et al. An overview of thymidine. Cancer 1980; 45: 1117-28.

7 Reichard P, Sköld O, Klein G, Revesz L, Magnusson PH. Studies on resistance against 5-fluorouracil. I. Enzymes of the uracil pathway during development of resistance. Cancer Res 1962; 22: 235-43.

8 Reyes P, Hall TC. Synthesis of 5-fluorouridine-5'phosphate by a pyrimidine phosphoribosyltransferase of mammalian origin. II. Correlation between the tumour levels of the enzyme and the 5-fluorouracil promoted increase in survival of tumour-bearing mice.
Biochem Pharmacol 1969; 18: 2587-90.

9 Fukushima M, Ikenaka K, Shirasaka T, Fujii S. Metabolism of 5-FU in sensitive and resistant tumour cells. Gann 1979; 70: 47-53.

10 Laskin JD, Evans RM, Slocum HK, Burke D, Hakala MT. Basis of natural variation in sensitivity to $5-\mathrm{FU}$ in mouse and human cells in culture. Cancer Res 1979; 39: 383-90.

11 Friedkin M, Roberts DJ. Enzymatic synthesis of nucleosides. I. Thymidine phosphorylase in mammalian tissues. Biol Chem 1954; 207 : 245-56.

12 Yamada EW. Pyrimidine nucleoside phosphorylases of rat liver. Separation by ion-exchange chromatography and studies of the effect of cytidine or uridine administration. Biol Chem 1968; 243: 1649-55.

13 Pontis H, Degerstedt G, Reichard P. Uridine and deoxyuridine phosphorylases from ehrlich ascitic tumour. Biochim Biophys Acta 1961; 51: 138-47.

14 Sköld O. Enzymes of uracil metabolism in tissues with different growth characteristics. Biochim Biophy Acta 1960; 44: 1-12. 